\title{
ESTIMATIVA DA POTÊNCIA CALORÍFICA LIBERTADA NO INCÊNDIO OCORRIDO NO TÚNEL DO MARÃO EM 2017-06-11
}

João Viegas ${ }^{1}$ Oliveira Costa ${ }^{2}$ Luis Sousa $^{3}$ Alcídio Correia $^{4}$

\section{RESUMO}

No dia 2017-06-11, pelas 20:29 h, ocorreu um incêndio de um veículo pesado de transporte de passageiros no interior do Túnel do Marão, sensivelmente a $1800 \mathrm{~m}$ após o portal de entrada e no sentido Porto-Vila Real. Embora não tendo causado vítimas, que puderam proceder à auto-evacuação usufruindo dos meios de segurança instalados no túnel, o veículo ficou totalmente destruído e causou danos significativos nos equipamentos instalados na galeria sinistrada. Devido a esses danos só foi possível reabrir ao tráfego a galeria sinistrada cerca de uma semana depois. Tratando-se do maior incêndio ocorrido em túneis rodoviários em Portugal, é relevante procurar obter uma estimativa da evolução da potência calorífica libertada ao longo do tempo. Nesta comunicação são utilizados os registos, nomeadamente de temperatura e de velocidade do escoamento, da instrumentação do túnel para se proceder à estimativa da potência calorífica libertada e da respetiva incerteza.

Palavras-chave: Túneis. Potência Calorífica. Dinâmica do fogo.

\footnotetext{
1 Investigador Principal do Laboratório Nacional de Engenharia Civil (LNEC), Av. do Brasil 101, 1700-066 Lisboa, Portugal.

2 Investigador Principal do Laboratório Nacional de Engenharia Civil (LNEC), Av. do Brasil 101, 1700-066 Lisboa, Portugal.

${ }^{3}$ Engenheiro das Infraestruturas de Portugal, Almada, Portugal.

${ }^{4}$ Engenheiro das Infraestruturas de Portugal, Almada, Portugal.
} 


\section{INTRODUÇÃO}

Embora o conhecimento da combustão de veículos pesados de transporte de passageiros constitua um elemento relevante para 0 dimensionamento dos sistemas de controlo de fumo de túneis, a informação existente é ainda relativamente escassa. Lönnermark e Ingason (2004) referem ensaios realizados no âmbito do projeto Eureka (INGASON et al., 1994a) e no túnel Shimizu (KUNIKANE et al., 2002) indicando que o pico da potência calorífica libertada ocorre 7 a 8 minutos após o início do incêndio e pode atingir cerca de $30 \mathrm{MW}$, sendo a energia libertada no incêndio de 41 GJ. No âmbito das publicações da Rede Temática FIT (2005) é referido o incêndio ocorrido no túnel Ekeberg (INGASON et al., 1994b),em Oslo, para o qual se estimou um crescimento da potência calorífica libertada durante 6 minutos até ao valor de $36 \mathrm{MW}$, com uma energia libertada no incêndio de $28 \mathrm{GJ}$. Wen-Sheng Hsu et al. (2017) analisaram o incêndio de um veículo pesado de transporte de passageiros ocorrido no túnel Hsuehshanem Taiwan em 2012-05-07, que causou 2 mortos e 34 feridos, e estimaram a potência calorífica libertada entre $25 \mathrm{MW}$ e $30 \mathrm{MW}$. Citam ainda Kunikane et al. (2002), de onde extraíram o gráfico que se apresenta na figura 1. Todos estes resultados são concordantes em apontar para uma gama para o pico da potência calorífica libertada entre $25 \mathrm{MW}$ e $36 \mathrm{MW}$. 


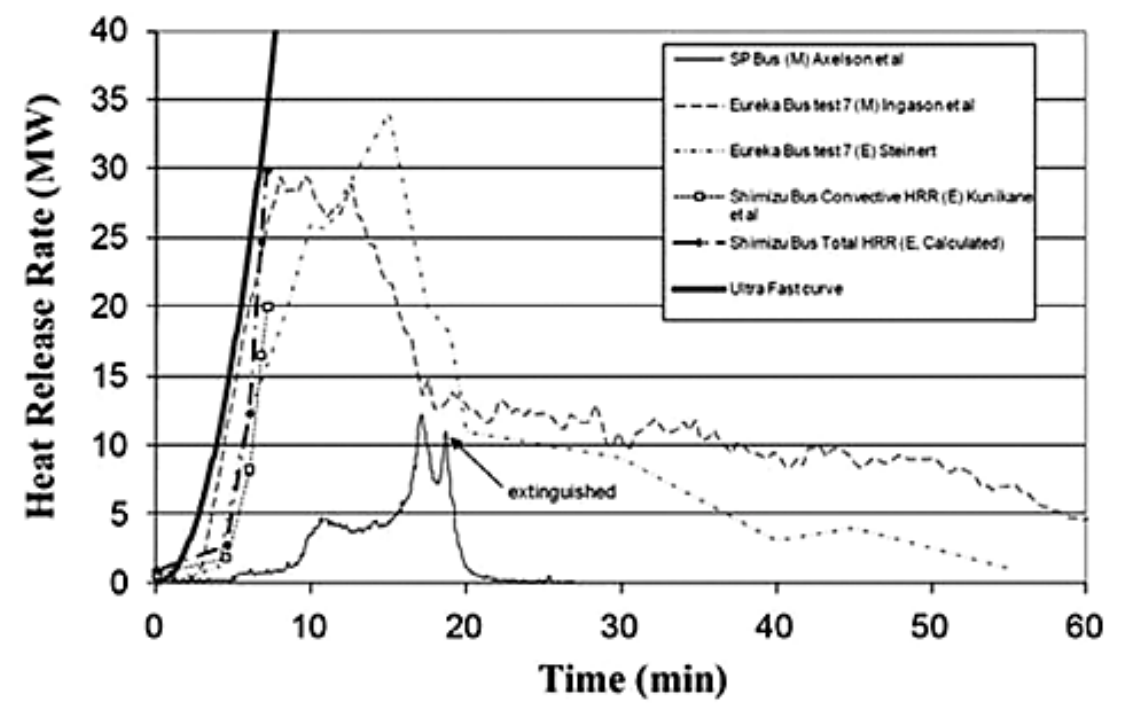

Figura 1: Potência calorífica libertada em veículos pesados de transporte de passageiros.

Fonte: Kunkane et al., 2002.

\section{METODOLOGIA}

A estimativa das temperaturas atingidas nos túneis em situação de incêndio é normalmente realizada com base numa avaliação de danos. Por sua vez, a potência de incêndio é usualmente estimada com base numa avaliação do combustível consumido. No presente caso, a disponibilidade de medições de velocidade do escoamento no interior do túnel, embora muito afetadas por fenómenos locais (por exemplo, a entrada de todos os meios de emergência na galeria sinistrada), constitui mais um elemento disponível para estimar a evolução térmica do evento que não deve ser ignorado, embora esteja sujeito a incertezas consideráveis. Tanto quanto é do conhecimento dos autores, a metodologia aqui utilizada é inovadora.

O túnel está equipado com um sistema Fibrolaser de deteção de incêndio ao longo de cada uma das galerias rodoviárias cujos registos, até à sua destruição local pelo incêndio na galeria sinistrada, permitem conhecer a 
evolução da temperatura no interior do túnel até ao momento do início do incêndio. A temperatura do ar exterior no portal de entrada foi registada através da estação meteorológica aí existente. No interior da galeria sinistrada existem três anemómetros ultrassónicos (o S-ANE-1 a 40 m, o S-ANE-2 a 2774 m e o S-ANE-3 a $5560 \mathrm{~m}$ do portal de entrada) que, devido a estarem localizados a uma distância razoável do local do incêndio, não foram afetados por este, permitindo conhecer as velocidades instantâneas do escoamento nessas secções.

Os anemómetros ultrassónicos do túnel fazem a medição da velocidade média do escoamento numa linha entre o emissor e o recetor do aparelho. Dado que a velocidade do escoamento na secção reta do túnel não é uniforme, existe um desvio entre a velocidade medida pelos anemómetros do túnel e a velocidade média do escoamento. Os trabalhos realizados aquando da abertura inicial do túnel ao tráfego (em 2016) permitiram relacionar as velocidades medidas por esses anemómetros com a velocidade média nas secções de medição. Na Tabela 1 estão indicados os fatores de correção a aplicar aos valores de velocidade lidos pelos anemómetros do túnel, que resultaram desta aferição, e as respetivas incertezas. $O$ valor de incerteza corresponde à incerteza expandida e inclui quer a variância da medição de velocidade pelo anemómetro de referência, quer a variância da medição de velocidade pelo anemómetro do túnel respetivo. Dado que há anemómetros do túnel que se situam a jusante de ventiladores de impulso e dentro da sua zona de influência, nesses casos a aferição efetuada só é válida quando esses ventiladores estão ativos (conforme indicado nas observações do quadro). A diferença, com algum significado, entre as correções dos anemómetros $S$ ANEM-2 e S-ANEM-3 relativamente à do S-ANEM-1 está relacionada com essa alteração ao perfil de velocidade na secção de medição. 
Tabela 1: Fatores de correção a aplicar aos valores de velocidade lidos pelos anemómetros do túnel

\begin{tabular}{cccc}
\hline Anemómetro & $\begin{array}{c}\text { Fator de } \\
\text { correção }\end{array}$ & $\begin{array}{c}\text { Incerteza } \\
\text { padrão } \\
{[\mathbf{m} / \mathbf{s}]}\end{array}$ & Observações \\
\hline S-ANE-1 & 0,743 & 0,41 & Só válido com os ventiladores S- \\
S-ANE-2 & 0,665 & 0,39 & $\begin{array}{c}\text { V-4 ativos. } \\
\text { S-ANE-3 }\end{array}$ \\
\hline
\end{tabular}

Foi inserido no sistema de automação do túnel um fator (com o valor de 0,657, correspondente ao fator de correção para o anemómetro S-ANE-3) selecionado de forma a assegurar que a velocidade do escoamento é regulada para proporcionar, em média, valores superiores à velocidade crítica. Assim, as velocidades medidas pelos anemómetros S-ANE-1 e S-ANE-2 estão ligeiramente abaixo do valor médio real para as secções de medição (nas condições em que foram avaliadas experimentalmente em 2016), pelo que foram corrigidas da seguinte forma:

$$
\overline{\overline{\text { medud }}_{1}} * 1,131=\overline{V_{\text {meduda }}} * 1,012=\overline{V_{\text {medud }} a_{n}}
$$

sendo $\overline{V_{\text {meduda }_{1}}}$ a velocidade média resultante da medição pela S-ANEM-i. Considera-se que os ventiladores de impulso posicionados antes dos anemómetros estavam ativos durante o incêndio, que estavam inativos antes do incêndio e que o escoamento pré-existente era exclusivamente devido a efeitos naturais (efeito de pistão e, eventualmente, efeito de chaminé). Nestas circunstâncias, pode admitir-se que a forma do campo de velocidades é similar nas secções de medição dos três anemómetros antes do incêndio, pelo que a sua comparação é relevante para se avaliar a consistência das medições dos anemómetros antes do incêndio. 
Verifica-se, através das medições do sistema fibrolaser, que a diferença de temperatura entre o portal oeste e o interior do túnel na meia hora antecedente ao incêndio é de $3,3^{\circ} \mathrm{C}$ (sendo mais baixa no interior). Tendo em conta a equação (2),

$$
\dot{m}_{1}=\dot{m}_{2}=\dot{m}_{3} \Rightarrow v_{1} A \frac{\rho_{0} T_{0}}{T_{1}}=v_{2} A \frac{\rho_{0} T_{0}}{T_{2}} \Leftrightarrow \frac{v_{1}}{T_{1}}=\frac{v_{2}}{T_{2}} \Leftrightarrow \frac{v_{2}}{v_{1}}=\frac{T_{2}}{T_{1}}
$$

na qual $\dot{m}_{\bar{i}}$ é o caudal mássico do escoamento na secção i, $v_{\bar{i}}$ e $T_{\bar{i}}$ são a velocidade média e a temperatura absoluta na secção i, $\rho_{0}$ e $T_{0}$ são a massa volúmica e a temperatura absoluta exterior, constata-se que a relação entre as velocidades registadas pelos anemómetros tem de verificar a seguinte relação:

$$
\frac{\overline{v_{\mathrm{ANE} 1}}}{\overline{v_{\mathrm{ANE} 2}}}=\frac{\overline{v_{\mathrm{ANE} 1}}}{\overline{v_{\mathrm{ANE} 3}}}=\frac{\overline{T_{\mathrm{S} 1}}}{\overline{T_{\mathrm{S} 16 \mathrm{~S} 20}}}
$$

Os valores $\overline{v_{\text {ANE } 1}}$ correspondem às medições realizadas pelo anemómetro S-ANEM-i corrigidas pela equação (1) e $\overline{T_{\mathrm{S}}}$ corresponde à temperatura média medida pelo sistema fibrolaser no setor $\mathrm{Si}$ (o setor S1 corresponde ao portal oeste e os setores S16_S20 correspondem ao interior do túnel. O erro que ocorre para as velocidades médias no período de 30 minutos antes da ocorrência do incêndio é de 1,7\% (aprox. 0,06 m/s), quando se comparam as velocidades medidas pelos anemómetros S-ANEM-1 e S-ANEM2, e de 4,6\% (aprox. 0,16 m/s), quando se comparam as velocidades medidas pelos anemómetros S-ANEM-1 e S-ANEM-3. A incerteza padrão estimada para a medição da velocidade média (indicada na Tabela 1) corresponde a valores significativamente superiores, pelo que se considera que esse erro está enquadrado pela incerteza da medição. 
Aplicando uma condição de continuidade (na comunicação evidencia-se que a abertura de portões das galerias transversais não influencia significativamente a condição de continuidade na galeria sinistrada), foi possível estimar a temperatura média do escoamento a partir da expansão térmica e estimar a potência calorífica convectada nas secções de medição, bem como a respetiva incerteza. A estimativa da potência calorífica convectada na secção do anemómetro i $\left(\dot{Q}_{\varepsilon_{-} i}\right)$ é dada pela expressão seguinte:

$$
\dot{Q}_{C_{-} i}=v_{1} A \frac{\rho_{0} T_{0}}{T_{1}}\left(c_{\mathrm{p}_{-} \mathrm{i}} \frac{v_{\mathrm{i}} T_{1}}{v_{1}}-c_{\mathrm{p}_{-} 1} T_{1}\right) \Leftrightarrow \dot{Q}_{c}=A \rho_{0} T_{0}\left(C_{\mathrm{p}_{\mathrm{i}} v_{\mathrm{i}}}-C_{\mathrm{p}_{-} 1} v_{1}\right)
$$

sendo $\mathrm{A}$ a área da secção reta do túnel e $C_{\mathrm{p}_{-\mathrm{i}}} \mathrm{O}$ calor específico na secção do anemómetro S-ANEM-i. As medições de velocidade foram realizadas continuamente de $10 \mathrm{~s}$ em $10 \mathrm{~s}$. Os resultados apresentados resultam da aplicação de uma média móvel de 300 s para suavizar as curvas.

A observação de filmes com a panorâmica do portal este, no qual ocorreu o escoamento do fumo da galeria sinistrada para o exterior, mostra que o fumo tem tendência a descer a encosta, o que evidencia que a temperatura do fumo que saía pelo portal terá sido inferior à temperatura ambiente no exterior, pelo menos no início do evento. Para se avaliar se a abertura de galerias transversais terá tido impacte significativo no escoamento, pondo em causa a condição de conservação do caudal entre a secção de medição do anemómetro S-ANEM-1 e a do S-ANEM-2 comparou-se o resultado da estimativa da potência calorífica convectada na secção de medição do SANEM-2 realizada de acordo com a equação (4) com uma estimativa realizada de acordo com a equação (5), na qual se toma como velocidade "fria" de referência a da secção de medição do S-ANEM-3 (admitindo-se que esta, no limite, se encontra à temperatura exterior) 


$$
\dot{Q}_{\varepsilon}=A \rho_{0} T_{0}\left(C_{\mathrm{p}_{2} 2} v_{2}-C_{\mathrm{p}_{-} 3} v_{3}\right)
$$

Foi estimado o valor de 14,3 MW para a incerteza padrão da potência calorífica convectada na seção de medição do S-ANEM-2. A temperatura média em cada secção do túnel pode ser estimada pela aplicação da equação da perda de calor em condutas [equação (6)], que pode ser adaptada para se estimar a temperatura média do escoamento na secção de incêndio (CENTRE D'ESTUDES DES TUNNELS, 2003):

$$
\begin{aligned}
T=T_{0}+\left(T_{\max }-T_{0}\right) e^{-\frac{x}{x_{\theta}}} \Leftrightarrow\left(T-T_{0}\right) e^{\frac{x}{x_{\theta}}}=\left(T_{\max }-T_{0}\right) \Leftrightarrow \\
\Leftrightarrow T_{\max }=\left(T-T_{0}\right) e^{\frac{x}{x_{\varepsilon}}}+T_{0} \\
x_{\varepsilon}=\frac{C_{p} \rho_{0} W_{0} D_{H}}{4 h_{\text {app }}}
\end{aligned}
$$

sendo $\mathrm{x}$ a distância a juzante do incêndio para a qual é estimada a temperatura $\mathrm{T}, W_{0}$ O valor da velocidade média do escoamento e $D_{H}$ o diâmetro hidráulico do túnel.Um valor limite do coeficiente de convecção médio $h_{a p p}$ pode ser estimado a partir das características térmicas do escoamento entre a secção de medição do S-ANEM-2 e do S-ANEM-3, sabendo-se que, no limite a temperatura na secção de saída (S-ANEM-3) corresponde à temperatura exterior. Considerando que a diferença de temperatura do escoamento entre secção do S-ANEM-2 e a secção de saída é de aproximadamente $60 \mathrm{~K}$ e tendo em conta que a temperatura inicial do túnel é cerca de $3 \mathrm{~K}$ inferior à temperatura exterior, é possível estabelecer a condição seguinte:

$$
\begin{gathered}
T=T_{\infty}+\left(T_{\max }-T_{\infty}\right) e^{-\frac{x}{x_{\theta}}} \Leftrightarrow \frac{T-T_{\infty}}{T_{\max }-T_{\infty}}=e^{-\frac{x}{x_{\theta}}} \Leftrightarrow e^{-\frac{x}{x_{\theta}}}=\frac{3}{60} \Leftrightarrow \\
\Leftrightarrow h_{\text {app }} \approx 10 \mathrm{~W} /\left(\mathrm{m}^{2} K\right)
\end{gathered}
$$


A publicação (CENTRE D'ESTUDES DES TUNNELS, 2003) indica uma gama de valores para o coeficiente $h_{a p p}$ compreendida entre $6 \mathrm{~W} /\left(\mathrm{m}^{2} \mathrm{~K}\right)$ e $14 \mathrm{~W} /\left(\mathrm{m}^{2} \mathrm{~K}\right)$, que varia com o tempo (contado a partir do início do incêndio) e com a velocidade do escoamento. $O$ valor encontrado enquadra-se na gama indicada; todavia, esta constatação não implica que o coeficiente $h_{a p p}$ tenha esse valor na secção compreendida entre o incêndio e a secção de medição do S-ANEM-2. Ainda assim, na ausência de melhor estimativa utilizou-se esse valor para estimar a temperatura e a potência calorífica convectada na secção de incêndio por aplicação das equações (6) e (7). Estimou-se o valor de $40 \mathrm{~K}$ (10,6\% da temperatura absoluta) para a incerteza padrão na secção de incêndio; esse valor permitiu a estimativa da incerteza da potência calorífica convectada na secção de incêndio representada na figura 4. A energia convectada no incêndio foi calculada por integração no tempo da potência calorífica convectada.

\section{RESULTADOS}

$\mathrm{Na}$ figura 2 apresentam-se as velocidades do escoamento medidas no período compreendido entre as 12:00:00 do dia 2017-06-11 e as 12:00:00 do dia 2017-06-12. A oval vermelha salienta o período de incêndio. No período anterior observa-se irregularidade na velocidade, contrastando com o período subsequente ao incêndio; as intensas variações de velocidade no período precedente ao acidente correspondem ao efeito de pistão produzido pelo tráfego, que se encontra naturalmente ausente no período subsequente ao incêndio (durante o qual a galeria permaneceu encerrada ao tráfego). As velocidades negativas correspondem a escoamento no sentido contrário ao do tráfego (sentido este-oeste do escoamento).

Observa-se que em períodos subsequentes ao incêndio os três anemómetros indicam aproximadamente as mesmas velocidades, o que 
corrobora a hipótese dos anemómetros (em especial o S-ANEM-2, que esteve exposto a temperaturas mais elevadas) não terem sido danificados durante 0 evento de incêndio, por se encontrarem suficientemente afastados deste.

$\mathrm{Na}$ figura 3 apresentam-se as velocidades do escoamento medidas no período entre as $20: 00 \mathrm{~h}$ e as $21: 30 \mathrm{~h}$, bem como a estimativa da potência calorífica convectada nas secções de medição dos anemómetros S-ANE-2 e SANE-3. No caso das curvas identificadas como S-ANEM-2 e S-ANEM-3 na legenda, o seu cálculo foi realizado com base na equação (4), tomando como referência a velocidade medida pelo S-ANEM-1; no caso da curva identificada como S-ANEM-2a na legenda foi utilizada a equação (5). Constata-se que as diferenças de amplitude entre as duas curvas que representam as estimativas da potência convectada na secção de medição do S-ANEM-2 estão enquadradas pela incerteza. Constata-se que a potência calorífica convectada terá tido um pico inicial de cerca de $35 \mathrm{MW}$ e que, no período subsequente, terá tido valores entre $20 \mathrm{MW}$ e $25 \mathrm{MW}$. Estima-se em 56,6 GJ a energia convectada nesta seção. Neste gráfico, uma redução do caudal escoado na secção de medição do S-ANEM-2 devido ao escoamento, através da galeria transversal, no sentido da galeria rodoviária sinistrada para a não sinistrada (o escoamento terá sido nesse sentido pelo facto de a montante do incêndio a galeria sinistrada se encontrar a uma pressão mais elevada do que a não sinistrada [8]) seria mostrada como uma redução da potência convectada; como não existe qualquer galeria transversal aberta a jusante do incêndio (entre as secções de medição do S-ANEM-2 e do S-ANEM-3), nesse caso a potência convectada calculada com base nos S-ANEM-2 e S-ANEM-3 seria superior à calculada com base nos S-ANEM-1 e S-ANEM-2, o que não é o caso. 


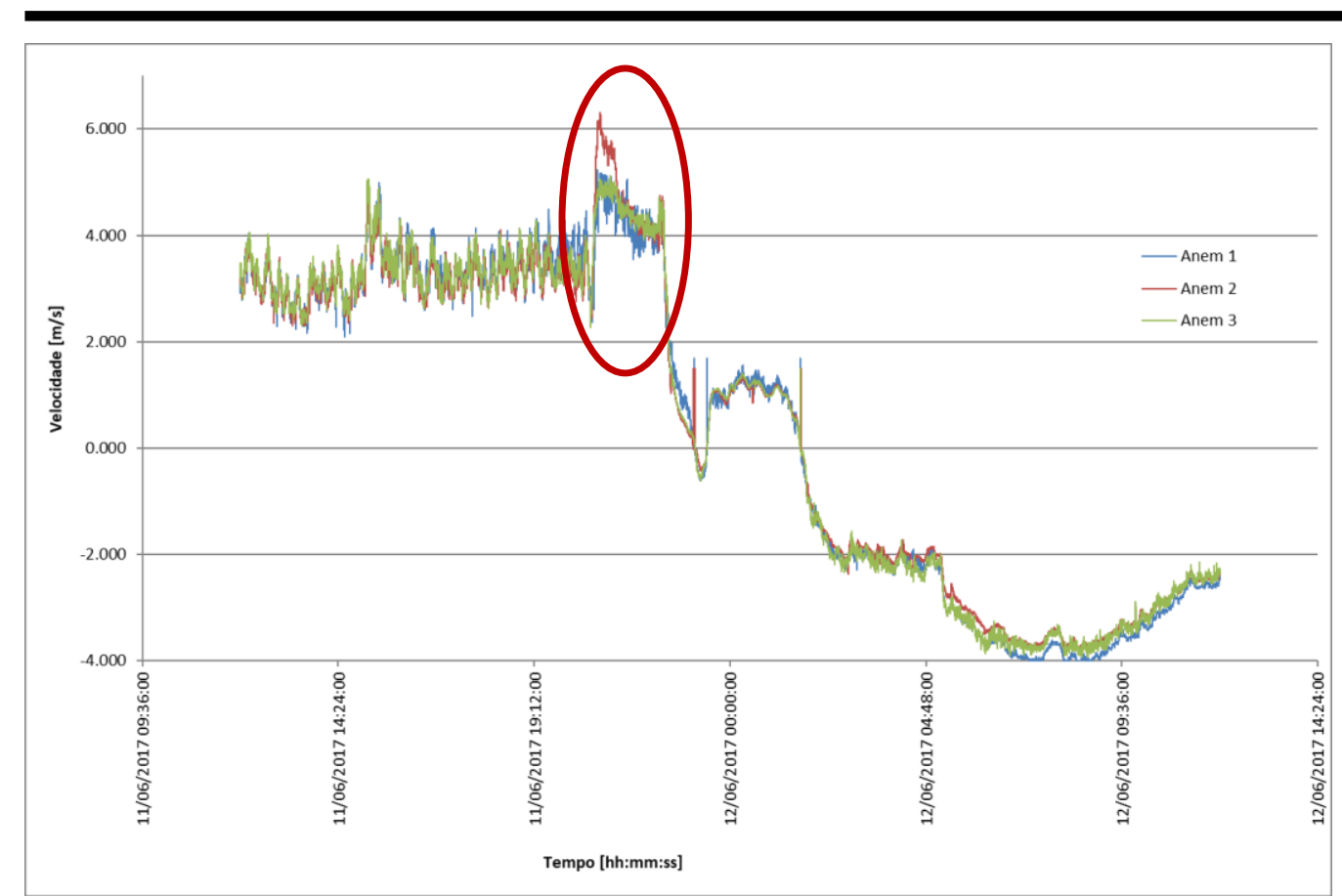

Figura 2: Velocidades do escoamento medidas no túnel entre as 12:00:00 do dia 2017-06-11 e as 12:00:00 do dia 2017-06-12.
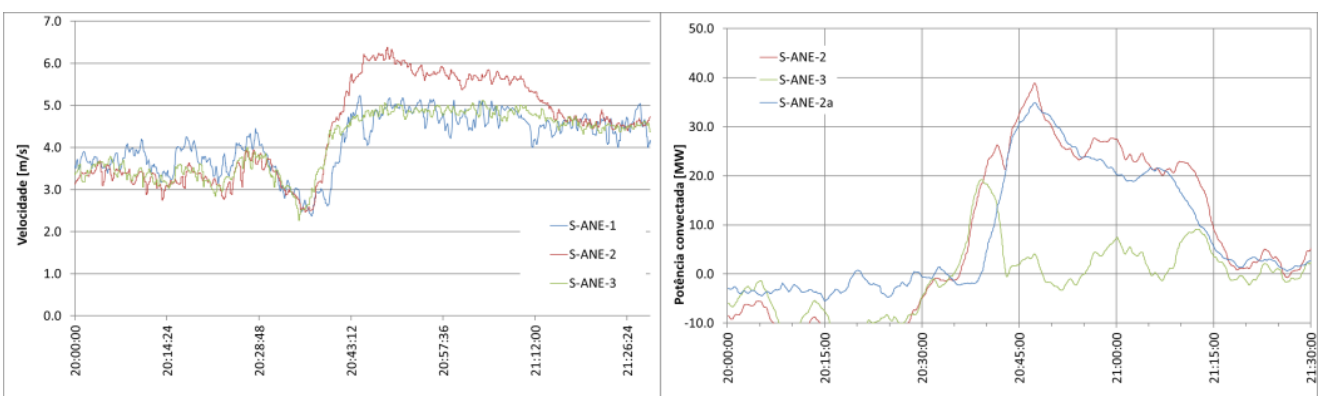

Figura 3: Velocidades do escoamento medidas no túnel e estimativa da potência calorífica convectada nas secções de medição dos anemómetros SANE-2 e S-ANE-3.

Salienta-se que na fase inicial do incêndio, durante cerca de $120 \mathrm{~s}$, a velocidade medida pelo S-ANEM-3 assume aproximadamente os mesmos valores da medida pelo S-ANEM-2; trata-se de um período em que a galeria rodoviária entre as duas secções de medição ainda está preenchida por ar frio, pelo que não ocorrem perdas de calor entre as duas secções de medição que conduzam a alterações do caudal volúmico. $O$ instante de tempo em que a frente de fumo atinge a secção do S-ANEM-2 é simbolizada neste gráfico pelo 
fim da coincidência entre a estimativa da potência calorífica convectada para as secções S-ANEM-2 e S-ANEM-3; o instante de tempo para o qual a estimativa da potência convectada na secção do S-ANEM-3 assume valores próximos de 0 corresponde ao momento em que a frente de fumo perdeu todo o seu calor para as paredes, piso e abóbada do túnel (o que é consistente com a observação de que o fumo que sai do túnel no portal este desce a encosta); numa fase inicial, o fumo pode ter perdido calor até atingir a temperatura inicial do túnel antes da frente de fumo chegar à secção do S-ANEM-3. O tempo de escoamento entre a secção de incêndio e a secção do S-ANEM-2 é de cerca de $230 \mathrm{~s}$, a que corresponde uma velocidade média de $4,1 \mathrm{~m} / \mathrm{s}$, o que é consistente com as velocidades apresentadas na figura 2 para este período. $O$ intervalo de tempo entre o fim da coincidência das potências caloríficas convectadas nas secções dos S-ANEM-2 e S-ANEM-3 e a redução para 0 na secção do S-ANEM-3 é de cerca de $240 \mathrm{~s}$, enquanto para uma velocidade de $5 \mathrm{~m} / \mathrm{s}$ a frente de fumo levaria $560 \mathrm{~s}$ para chegar à secção do S-ANEM-3 partindo da secção do S-ANEM-2, o que é consistente com a justificação referida.

$\mathrm{Na}$ figura 4 apresenta-se a estimativa da temperatura e a estimativa da potência calorífica convectada no local do incêndio e nas secções dos SANEM-2 e S-ANEM-3. Apresenta-se também a curva que representa a dedução do valor da incerteza padrão à estimativa da temperatura.

A curva que representa o limite inferior da potência calorífica convectada no local do incêndio resulta do cálculo da potência convectada com base no valor da temperatura deduzido do valor da incerteza padrão. Salienta-se que para estas estimativas tomou-se 0 valor $h_{\text {app }}=10 \mathrm{~W} /\left(\mathrm{m}^{2} \mathrm{~K}\right)$. 


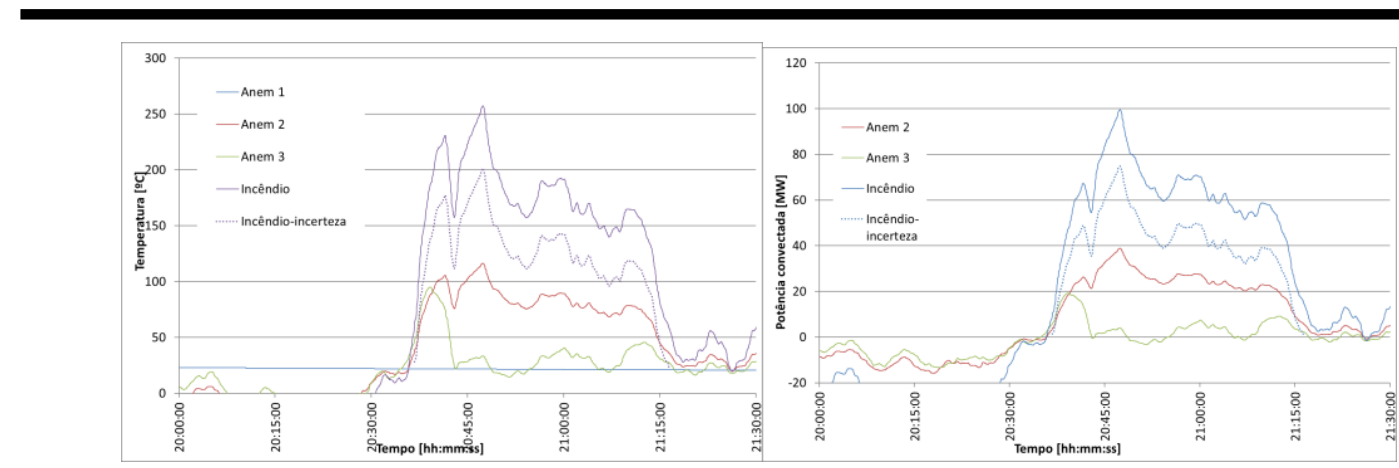

Figura 4: Estimativa da potência calorífica convectada no local do incêndio e nas secções dos S-ANEM-2 e S-ANEM-3.

Com base nestes resultados, estima-se em $145 \mathrm{GJ}$ a energia convectada pelo incêndio, sendo 98 GJ o valor que se obtém com base no valor da temperatura deduzido do valor da incerteza padrão. Se for considerado um coeficiente de convecção médio $h_{a p p}=6 \mathrm{~W} /\left(\mathrm{m}^{2} \mathrm{~K}\right)$, o que será porventura muito baixo para este incêndio, obtém-se 100 GJ para a energia convectada pelo incêndio, sendo 58 GJ o valor que se obtém com base no valor da temperatura deduzido do valor da incerteza padrão. Note-se que haverá ainda uma parte da energia libertada pelo incêndio que terá sido perdida por radiação, o que não está aqui contabilizado.

Os valores obtidos quer para a potência calorífica quer para a energia convectada encontram-se acima dos valores de 25-36 MW e de 28-41 GJ referidos em bibliografia, mesmo tendo em conta a incerteza, pelo que os resultados deste estudo devem ser encarados de forma cautelosa. Assinala-se, todavia, que uma área significativa do pavimento betuminoso foi destruída pelo fogo; tendo em conta o seu elevado poder calorífico inferior (tem o valor de 40,2 MJ/kg [9]), não deve ser excluída a hipótese de que a combustão do betuminoso possa ter contribuído para 0 incêndio. Considera-se que este estudo deverá ser aprofundado através de uma simulação mais detalhada (por exemplo, através de mecânica de fluidos computacional) das perdas de calor entre o local do incêndio e a secção de medição do S-ANEM-2, uma vez que este aspeto revela ser determinante na estimativa da potência de incêndio. 
Para além disso, seria muito relevante conhecer as massas e naturezas dos materiais que constituíam o autocarro, para se ter uma estimativa da sua carga de incêndio.

\section{CONCLUSÕES}

Calcula-se que a potência calorífica convectada na secção de medição do anemómetro possa ter atingido cerca de $35 \mathrm{MW}$, estimando-se uma incerteza padrão de 14,3 MW. A estimativa da potência calorífica convectada na secção de incêndio aponta para valores excessivamente elevados quando comparada com a informação conhecida por via bibliográfica, mesmo tendo em conta a estimativa da incerteza. Por essa razão, os valores que resultam deste estudo devem ser considerados de forma cautelosa enquanto não for encontrada uma justificação para este aspeto. Admite-se que uma hipótese a considerar esteja relacionada com a eventual contribuição da combustão do pavimento betuminoso. Futuramente deverá ser analisada a perda de calor entre o local de incêndio e a secção de medição do S-ANEM-2 com metodologias mais robustas, por exemplo recorrendo a mecânica de fluidos computacional.

\section{REFERÊNCIAS}

CENTRE D'ÉTUDES DES TUNNELS - Dossier Pilote des Tunnels. Equipements. Ventilation. IBSN 2-11-084740-9, 2003.

DIÁRIO DA REPÚBLICA. Despacho n.․ 17313/2008. Diário da República, 2. a série - N. $.0122-26$ de Junho de 2008.

FIT - Fire in Tunnels. Technical Report - Part 1 Design Fire Scenarios. Thematic Network FIT - Fire in Tunnels, 2005.

INGASON, H., GUSTAVSSON, S., and DAHLBERG, M., "Heat Release Rate Measurements in Tunnel Fires", SP Report 1994:08, Swedish National Testing and Research Institute, 1994a. 
INGASON, H.; GUSTAVSSON, S.; DAHLBERG, M. Heat Release Rate Measurements in Tunnel Fires, SP Report 1994:08, Swedish National Testing and Research Institute, 1994b.

KUNIKANE, Y, KAWABATA, N., ISHIKAWA, T., TAKEKUNI, K., and SHIMODA, $A$, "Thermal fumes and smoke induced by bus fire accident in large cross sectional tunnel", The Fifth JSME-KSME Fluids Engineering Conference Nov., p. 17-21, Nagoya, Japan, 2002.

LÖNNERMARK, Anders; INGASON, Haukur - Recent Achievements Regarding Heat Release and Temperatures during Fires in Tunnels. Safety in Infrastructure - Svédületes!, Budapest 20th-21st October, 2004.

VIEGAS, João; OLIVEIRA COSTA, Carlos; MONTEIRO, Bernardo e PEREIRA, Paulo. Impacte das diferenças de pressão geradas pelo controlo de fumo em túneis. $6^{a}$ s Jornadas de Segurança aos Incêndios Urbanos, 29nov18, Coimbra, 2018.

WEN-SHENG, Hsu; YU-HSIANG, Huang, TZU-SHENG, Shen; CHIH-YUAN, Cheng; TSUNG-YUEH Chen. Analysis of the Hsuehshan Tunnel Fire in Taiwan. Tunnelling and Underground Space Technology 69 (2017) p.108-115, 2017. 